International Journal of Humanities and Social Sciences

p-ISSN: 1694-2620 | e-ISSN: 1694-2639

Vol. 13, No. 1 (2021), pp. 46-55, CIJHSS

https://doi.org/10.26803/ijhss.13.1.5

Received Jan 26, 2021 | Revised Apr 29, 2021 | Accepted May 7, 2021

\title{
The Impact of Gender-neutral Communication on Brand Equity: A Study on Children Apparel Industry
}

\author{
Matteo Coggiola \\ Luiss University \\ Rome, Italy \\ Ivan Coste-Manière \\ SKEMA Business School \\ Sophia Antipolis, France
}

\begin{abstract}
This work wants to analyze the impact of communication on Brand Equity, by comparing a gendered and an ungendered type of advertising relative to a brand of children apparel. The idea of this work comes from the acknowledgement that, to the current situation, there is little research on the pro/cons of the usage of a type of communication alternative to the traditional one and free of gender stereotypes, and on its objective consequences on brand dimensions. The study was conducted using a posttest-only control group design: participants were randomly assigned to two groups, control and intervention, and were presented with two different stimuli (a gendered and a gender-neutral one). Convenience sampling has been adopted for this research and an online closeended response questionnaire was used for data gathering. A total of 152 responses were ultimately used in the study. The study challenges the argument that gender stereotypes are efficient tools to be used in communication to elicit a positive response and generate clearer brand associations in the viewer. The results showed how a gender-neutral type of communication has an overall positive effect on Brand Equity dimension, and how this result varies according to the age range of respondents, showing a substantial gap between Gen Z and elderly generations.
\end{abstract}

Keywords: gender; gender-neutral; brand equity; fashion; marketing

\section{Introduction}

\subsection{The "Gender" Debate}

One of the very first topics addressed by the work is the debate about the term "Gender". Different authors have voluntarily avoided trying to give universal meaning to the term, considering it more as a question, or a starting point for further analysis. Others have tried to define gender more precisely, according to either a generalist approach, which affirms the presence of common characteristics, conditions and experiences among men and women, which eventually end up in differentiating some individuals as men and some others as women, or to a particularistic perspective, which argues that gender is constructed independently of these "common criteria". Afterwards, the main steps of the so-called sex/gender debate have been discussed in detail: from an early existentialist approach, according to which masculinity and femininity are different by nature, until reaching the "doing gender" perspective of West and Zimmermann (1987), where 
gender is considered as something socially constructed, which differs across cultures, contexts and periods. The essentialist theories have often been criticized by modern literature for their attempt to establish, through the imposition of a universally accepted narration of gender, a discriminatory type of society, that is referred to as ordine veterosessuale. According to the essentialist theory, the division between men and women, therefore the validity of the binary paradigm, derives from the observation of objective reality. Nevertheless, our understanding of the world always goes through the mediation of a culture; a culture, in turn, is constructed through communication, and it is through communication that we know how to split the world into categories and how to interpret reality. In the specific case of gender categories, it happens that the categorization of reality has been always influenced by the strong patriarchal connotation of society. Therefore, the naturalization of the man/woman binomial, which is instead created by society, leads to the acceptance of some characteristics as necessary and immutable, while in reality, they are just functional in maintaining the social order which originated them.

Today it is generally recognized that gender is a fluid concept, something constantly reshaped through social interactions, which concerns the expression of the self. In the same way, it is universally understood how fundamental in its social function, on a communicative level: from politics to business, to embrace, ultimately, the entire collectivity, gender differentiation has represented a fundamental differentiation for efficiently delivering messages that are consistent with the chosen receiver. For this reason, gender has always been inevitably linked to fashion, for its ability to create and modify continuously individuals' identities, precisely by exploiting gender relations which stand at the base of society, eventually affecting the same notions of masculinity and femininity. For this reason, gender has always been inevitably linked to fashion, for its ability to create and modify continuously individuals' identities, precisely by exploiting gender relations which stand at the base of society, eventually affecting the same notions of masculinity and femininity. As Crane (2000) highlights, one of the principal messages conveyed by fashion and clothing style is the perception of gender roles by the individual and by society as a whole.

\subsection{Gender and Communication}

The analysis of gender roles and related behaviours has always been a critical tool for marketers, especially in the fashion industry, who wanted to easily segment their audience. Darley and Smith (1995) identified three main factors for which gender has been always used in marketing segmentation: gender segmentation is easily identifiable and accessible, and each segment comprises on average half of the population. Gendered advertising continues to constitute a major part of the current panorama, with the previously mentioned binary scheme which still constitutes a useful framework for the construction and delivery of the marketing message. However, many authors highlight how, in the so-called era of post-modern marketing, gender identities have increasingly become a malleable instrument of self-expression, with the very meaning of masculine and feminine deconstructed and reused to create new significances. The smartest brands have started to answer the consumers' request, in particular from Gen Z and Millennials, to embrace a more gender-fluid style of communication; with the challenge of traditional patterns and the creation of new paradigms, brands must adapt to these changes. The Luxury and Fashion industry has been a vanguard in spreading this revolution, with brands tackling the issues in mainly two ways: some have labelled themselves as unisex, while others have challenged explicitly gender stereotypes.

When it comes to the topic of gender fluidity associated with children, the debate becomes even more heated. As gender is one fundamental part of everyone's identity, the question of whether to raise kids outside of traditional gender boundaries, to give them enhanced freedom to express themselves, is still generating lots of different answers, from opposite points of view. Since researches that have been done up to now have provided significant data in support and opposition to an ungendered education pattern, there is no definitive answer to this social discussion. It is undeniable that the whole debate touches also the world of children's clothing, being apparel, as 
already stated, one of the fundamental means of expression of the gender identity of individuals. This idea of dressing children with a gender-neutral outfit, contrary to common belief, constituted the norm for a long time, as boys and girls used to wear the same clothes, usually made of white cotton, easy to bleach and non-restricting. At the end of the war, marketers started to understand the need to create a code for children's apparel, to appeal to mothers and convince them to buy more merchandise, and that's when the current blue/pink gender code has been set up. Despite this "color shift" could appear as irrelevant, researches have demonstrated that this fact has contributed to increase gender stereotyping in the U.S., making children aware of the importance social distinction of gender, and encouraging them to question themselves on what is "for boys" or "for girls". This gender-colors association, despite being assimilated today as a usual marketing tool, risks to expose gender non-conforming kids to mockery by society, just for the reason that they have a different color preference respect to the mass.

\subsection{The Rise of New Generations of Consumers}

The awareness of such issues is fundamental for those brands which want to stay competitive in a long-term perspective. It is clear how the role of the brand has undergone a substantial change over the years. From being a simple guarantee of quality, a whole new universe has begun to open behind the process of "branding". Today, companies are experiencing growing pressure from their consumer base to get involved in the most relevant socio-political issues, taking a strong stand in the debate. Companies should be aware of the main social issues which are developing around them, in their specific sector or industry, and should be ready to provide convincing responses to critiques and showing and demonstrating an authentic purpose by keeping a reserve of proactive initiatives on those issues. This additional dimension can be summarized by the word "Purpose", which far from remaining just a trend, is being more and more considered as a norm to which companies should adapt in order to obtain positive responses from the engagement of their customers. A strong Purpose is capable of increasing customers' loyalty, as already mentioned, and also of expanding the current customer base, as new consumers would be more willing to try the products. Almost $60 \%$ of Gen Z or Millennials worldwide believe in the importance of companies' social responsibility, particularly related to human rights, race, and LGBT rights, with respect to a smaller $50 \%$ of Boomers (Accenture, 2018). This is a fact to be taken into consideration, considering, in particular, the Luxury and Fashion industry, as, by 2025, more than half of the entire L\&F market will be constituted by Gen Y and Z (Bain \& Company, 2018). The sensibility of fashion customers to certain topics is constantly shaping the way the whole industry is moving and this spirit of inclusion and openness to people could not exclude the gender sphere. The strong voice of the youngest consumers' generations, combined with their growing volume and weight in the market, is pushing companies to work for the creation of a gender-inclusive work environment and a type of communication that turns away from classical gender stereotypes.

Researchers have always been concordant in affirming the positive consequences, for brands, stemming from the use of gender stereotypes as it has been usually associated with more positive associations generated in the consumer and a clearer brand positioning. On the other side, there is still little research on the effects that a gender-free type of communication, alternative to the traditional one, could have on brand dimensions, such as brand equity.

\section{Literature Review and Research Framework}

\subsection{Research Objective and Review of Literature}

The objective of this research is precisely to test the differential effect of traditional (gendered) and gender-neutral advertising on brand equity. The research's literature review has shown how marketing communication has a fundamental role in shaping the brand equity of a brand and how advertising is capable of manipulating brand equity, acting on its components (Krishnan 1990, Cobb-Walgren 1995, Aaker \& Biel 2013). Therefore, literature provides a solid foundation to structure this research on a conceptual framework which displays a causality relationship between 
communication and brand equity. A substantial part of the work has been dedicated to the review of main brand equity models, with a summary of the most used dimensions, used by different authors in order to operationalize the brand equity concept. Among the several variables proposed, brand associations and brand attitudes have been found of particular relevance for the purpose of this research. Based on the literature review, it can be stated that the two brand dimensions are universally recognized as two antecedents of brand equity, having the capability of affecting it, through both a direct and indirect effect (Aaker 1991, 1992; Chaudhuri, 1995; Faircloth et al., 2001, Chang, 2008; Keller, 2013). For this reason, it has been decided to measure the effects of communication on brand equity through these two variables. Throughout the review of existing academic literature, it has been explored and confirmed the effect advertising has on these variables. Several studies have analyzed how marketing communications can affect brand equity through the manipulation of brand associations and attitude (Ray, 1982; Krishnan, 1990; CobbWalgren, 1995; Orth and Holancova, 2003; Feiereisen et al., 2009; Aaker and Biel, 2013;. Lieven et al., 2014; Huhmann et al., 2016). The effect of advertising on brand equity is also measured through an alternative channel, that is the one passing from consumer affective response to the Ad. Emotional response to advertising has a direct contribution in the construction of brand equity and a mediating role in the relationship between communication and equity (Gardner, 1985; MacKenzie et al., 1986; Edell \& Burke, 1987; Stayman \& Aaker, 1988; Brown and Stayman, 1992; Bravo et al., 2007; Kim, Ratneshwar and Thorson, 2017).

\subsection{Comparative View and Formulation of Hypotheses}

The review of literature has provided some starting points to formulate the research's hypotheses.

First of all, all the reviewed works have corroborated the existing relationship between communication and Brand Equity, and its capacity to manipulate both Brand Associations and Brand Attitudes dimensions. These variables have been generally considered as two fundamental antecedents of brand equity by several authors. Anyway, other reviewed works have taken in consideration different dimensions, through which it is possible to determine the effects of a selected variable on Brand Equity. At the same way, authors have proposed different indicators capable of measuring the emotional response of the viewer to a displayed advertisement. Nonetheless, Emotional Response to Advertising appears to be the only one which can directly contribute to the building of Brand Equity.

Briefly summing up, these considerations led to the formulation of the following research's hypotheses:

Table 1 - Research Hypotheses

\begin{tabular}{|l|}
\hline $\boldsymbol{H}_{1}:$ Gender-Neutral Communication impacts Brand Equity \\
\hline $\boldsymbol{H}_{2}:$ Gender-Neutral Communication impacts Brand Associations \\
\hline $\boldsymbol{H}_{3:}$ Gender-Neutral Communication impacts Brand Attitudes \\
\hline $\boldsymbol{H}_{4}:$ Gender-Neutral Communication impacts Emotional Response to Advertising \\
\hline
\end{tabular}

\subsection{Design}

The proposed theoretical framework suggested the adoption of a causal type of research design, for this study. Causal research, also called explanatory research, allows to better investigate the nature and the magnitude of relationships which are based on a "cause-and-effect" principle. Since our purpose is to analyze the causal effect of marketing communication on the brand equity dimension, this research methodology appears to be the most suitable one for this scope. The nomothetic causal relationship which wants to be demonstrated through this study has been expressed through the proposed hypotheses. The research of primary data for such type of research is generally made through experiments, and a questionnaire was set up to answer the research question. The use of the experimental study allows to control for external factors which 
could incorrectly affect the results of the research. The model chosen for the design and implementation of the questionnaire is the posttest-only control group design. In order to observe the differential effect between gendered advertising and gender-neutral one, it occurred the necessity of setting up two separate groups, one for control and one for intervention. The comparison between two groups is considered as one of the fundamental elements of experimental design.

Despite a quantitative type of research like the one proposed here usually requires a probability sample, for a matter of costs and time, convenience sampling has been considered as the most appropriate sampling strategy to use. Literature demonstrates how convenience sampling, though being a nonprobability sampling strategy, is used in both qualitative and quantitative research (De Carlo, 2018). Participants were divided among the control and the intervention group, thanks to the tools of Qualtrics, which allows the creation of a single questionnaire, with the only difference in the stimulus provided, and the random division of respondents into two groups.

\subsection{Procedure}

In order to obtain the information needed for this research, a quantitative type of questionnaire with closed-ended responses was prepared. The proposed survey was exactly the same for the control and intervention group, with the only difference lying in the stimulus displayed to the respondents: a gendered one in the first case, and a gender-neutral one for the latter. The two stimuli were meant to be different in the representation of the children in the particular context; children characters are portrayed through gender stereotypes in the first setting, while depicted without this stereotyped frame in the second situation.

\subsection{Materials}

The stimulus provided to the respondent is a visual one. Literature has widely confirmed how the visual medium is particularly effective in the transmission of information, as people tend to recognize and process images faster than what they do with words and with less effort. According to Rashotte (2003), the visual representation of a non-verbal act or behavior is more impacting than its written description. Furthermore, the processing of visuals and emotions happens in the same area of the brain, and that is the reason why these two things are connected and end up generating long-lasting memories and strong impressions. To overcome the difficulty in finding two images which could represent an adequate stimulus for the sake of research, that is to say, capable of respecting the previously mentioned "laboratory conditions" of the experiment, the visual stimuli for the survey have been created ex-novo with photo mounting and editing. This allowed to control for external variables which could somehow affect the final result. The first image presents a gender-stereotyped setting, while in the second one the stereotypes are removed, to represent a more gender-neutral situation.

\subsection{Measurement}

The tool used to measure the variables involved in this experiment is the well-known Likert Scale. Likert scale is one of the most used rating scales, used in the measurement of people's attitudes toward a statement, more precisely the degree to which an individual expresses himself as favorable or not to it. For the sake of this study, it has been decided to adopt a 7-points Likert scale for the measurement of the variables involved. With respect to brand associations, the study has been referring to the work of Lassar, Mittal and Sharma and the scale they developed for their research on the measurement of CBBE. For the purpose of the study, greater attention has been placed on the analysis of three particular dimensions, among the five provided in the scale, namely social image, trustworthiness and attachment. Therefore, from an original set of 17 items, we ended up in adopting a scale of 10 items, in order to measure brand associations. For what concerns brand attitudes, the creation of a measurement scale has been again the result of a review of different studies. The proposed scale comes from a meta-analysis of the work from Miller (1971), 
Flaherty and Pappas (2000), Yoo and Donthu (2001), Chang (2008) and Van Horen and Pieters (2017), resulting in a combination of the items suggested by the different authors. With regard to affective response to ad, the present research refers to the work of Kim, Ratneshwar and Thorson (2017) and Green and Brock (2000), as reported in the Marketing Scales Handbook of Bruner (2019).

\section{Data Analysis and Discussion}

\subsection{Data Summary}

Overall, 211 people participated in the study, taking part to the questionnaire. Among these, 152 managed to fully complete the survey $(72 \%)$, on a total of 211 interactions. Thus, 59 responses were not taken in consideration, because they were incomplete and could generate biases in the data analysis. People were heavenly divided among the 2 groups, resulting in 76 valid responses for the control group, and 76 for the intervention group. Again, the two groups resulted in a balanced composition. The control group was composed for $51.32 \%$ of males, and $46.05 \%$ of females, while in the intervention group, these percentages were exactly inverted $(46.05 \%$ males and $51.32 \%$ females). Roughly half of both groups was represented by young people between 18 25 , who accounted for $51.32 \%$ of the control group and $44.74 \%$ of the intervention group.

\subsection{Reliability Analysis}

Reliability analysis of the three scales used in the study has been run on SPSS. The objective of this analysis was to test the overall reliability of the scales, and the single contribution of the different items. This methodology allows to test for internal consistency reliability, measured through Cronbach's alpha coefficient, which is expected to be above 0.70 to be acceptable, and equal or greater than 0.80 to demonstrate even stronger reliability. All the scales adopted in the study had been already tested for reliability, with positive outcomes, and used in different studies.

Table 2 - Reliability Analysis Results

\begin{tabular}{|l|l|}
\hline Scale Used & Cronbach's alpha value \\
\hline Brand Associations & $\alpha=0.950$ \\
\hline Brand Attitudes & $\alpha=0.960$ \\
\hline Emotional Response to Advertising & $\alpha=0.954$ \\
\hline
\end{tabular}

\subsection{ANOVA Testing}

The objective of the study was to determine if there could be any significant difference in the mean of the two groups, following the exposition to two different visual stimuli. In order to do that, data gathered with the survey were exported on SPSS and then analyzed through a one-way ANOVA (Analysis of Variance).

In this analysis, a significance level of 0.05 was adopted, meaning a $5 \%$ risk of incur in a type I error.

The F-test run on the three dependents verified the equal variances assumption for each of the variables involved. In each case, the test confirmed that the hypothesis that variances of groups are homogenous (homoscedasticity of variances) cannot be rejected. The other two assumptions for ANOVA were met as well, namely the assumption of independent observations (each record is independent) and the one for normality (one-way ANOVA is considered to be a robust test against the assumption of normality if the size of samples is enough large, namely $>25$ ). Once the assumptions have been verified, the analysis has gone further with hypothesis testing.

For all the variables involved, it was registered an increase in score in favor of the intervention group. Even though these numbers have been encouraging, considering the objective of the research, the statistical significance of the results had to be checked using the ANOVA test. The analysis of variances brought to the rejection of two null hypotheses, and the non-rejection of the other two. 
Table 3 - ANOVA Testing Outcome

\begin{tabular}{|l|l|}
\hline Hypothesis & Outcome \\
\hline $\begin{array}{l}\mathrm{H}_{1}: \text { Gender-Neutral Communication } \rightarrow \\
\text { Brand Equity }\end{array}$ & Null Hypothesis Rejected \\
\hline $\begin{array}{l}\mathrm{H}_{2}: \text { Gender-Neutral Communication } \rightarrow \\
\text { Brand Associations }\end{array}$ & Null Hypothesis Rejected \\
\hline $\begin{array}{l}\mathrm{H}_{3}: \text { Gender-Neutral Communication } \rightarrow \\
\text { Brand Attitudes }\end{array}$ & Null Hypothesis Not Rejected \\
\hline $\begin{array}{l}\mathrm{H}_{4}: \text { Gender-Neutral Communication } \rightarrow \\
\text { Emotional Response }\end{array}$ & Null Hypothesis Not Rejected \\
\hline
\end{tabular}

The result of the test demonstrated that there is no significant effect of gender-neutral communication on Brand Attitudes and Emotional Response to Advertising, while there is a statistically significant and positive effect on Brand Associations and on overall Brand Equity.

Effects of gender-neutral communication on brand associations were measured through the adoption of a modified version of the Brand Associations scale proposed by Lassar, Mittal and Sharma (1995). The Likert scale included a total of 10 items. The one-way ANOVA demonstrated there was a significant effect of gender-neutral communication on Brand Associations. The results suggested that there was a remarkable difference in means among the control and intervention group (+0.5763), and that this result was statistically significant $(\mathrm{F}(1,150)=6.098, \mathrm{p}$ value $<.05)$.

The dimension of Brand Attitudes was analyzed through a Likert scale of 5 points. Despite a substantial difference in the mean score among the two groups $(+0.4711)$, the one-way test did not manage to prove that this outcome was statistically significant $(\mathrm{F}(1,150)=3.096$, p value $>$ $.05)$.

With regards to Emotional Response, as well as it happened for the two previous variables, data highlighted a positive change of mean score in favour of the gender-neutral stimulus $(+0.4448)$, but further ANOVA does not find enough evidence to consider this gap statistically significant $(\mathrm{F}(1,150)=2.889$, $\mathrm{p}$ value $>.05)$.

Finally, in order to test the main hypothesis $\mathrm{H}_{1}$, first of all it has been necessary to create a new index, comprising of all three single dimensions. Therefore, through SPSS, a new variable defining Brand Equity has been computed, using the "mean" function. Once created this new element, one-way ANOVA was again used to decide whether to reject or not the null hypothesis. The descriptive analysis run on the variable had previously shown a substantial variation in the mean between groups ( +0.4974$)$, and the ANOVA test contributed to validate this result, from a statistic point of view. The one-way analysis confirmed that Brand Equity had been significantly affected by gender-neutral communication $(\mathrm{F}(1,150)=4.475$, $\mathrm{p}$ value $<.05)$.

\subsection{Descriptive Analysis}

In parallel to hypothesis testing, the analysis on the responses gathered, divided for age range, has been run to answer our second research question. Firstly, a comparison of the mean scores allowed to make a first distinction between the four different age groups targeted for the survey: two groups, namely Generation Z (18-25yo) and Baby Boomers $(>60)$, have appeared to be contributing to the positive gap in mean score of brand equity, in favor of the group of intervention. On the other side, Millennials (26-40yo) and Generation X (41-60) have registered better scores in the control group. In order to give more statistical relevance to the abovementioned results, independent $t$-tests were run on dummy variables which wanted to confront the responses obtained. Using the "recoding" option, a new variable has been created, to do a comparison between members of Gen Z and Millennials. Despite not finding enough evidence to confirm the statistical significance of the mean gap $(+0.71532)$ in the intervention group ( $p$ value $>.05)$, the software provided a different result with regard to the control group: the gap in mean 
score among the two groups (-1.25100), relative to the control set, was found to be statistically significant $(\mathrm{p}$ value $<.05)$. At the same time, another $\mathrm{T}$-test investigated the differences registered among the age range of Gen Z and Gen X. The result was the same as the one obtained for the previous group: the effect on the dependent variable was considered not relevant with regard to the intervention group $(+0.70728$; p value $>.05)$, fact that was not true as well for the parallel analysis on the control group (-1.02613), which ascertained the statistical significance of the assumptions previously made ( $\mathrm{p}$ value $<.05)$.

\subsection{Results}

The study, despite presenting contrasting results, demonstrated the significant impact generated on brand equity by gender-neutral communication. Contrary to what sustained by a great part of the literature reviewed (see paragraph 2.2.4), which always affirmed the importance of stereotyped representation of masculinity and femininity in generating clear and positive associations in the viewer (Lieven et al., 2014; Fugate \& Phillips, 2010), this research demonstrated how a communication stimulus deprived of those stereotypes is capable of building clearer and stronger associations than its gendered counterpart. Surprisingly, despite a similar change of mean, null hypotheses related to Brand Attitudes and Emotional Response to advertising were not rejected. The result is particularly unexpected if we consider that the hugest gap in mean score was registered precisely for Brand Attitudes variable. A lack of evidence for demonstrating significance for both dimensions, could be due to the low suitability of some items to the specific context of research and, most of all, to the stimulus proposed in the survey. It is reasonable to assume that, given only the visual stimulus proposed, for respondents, it was quite difficult to provide a valid score to questions of the scales. The dimension of Emotional Response deserves, in addition, a separate consideration: the use of an image, although respecting the experimental conditions, has been likely to not being enough to stimulate viewers' emotions and allow them to correctly select the scores relative to this variable. Probably the most important result, considering which was our first declared objective of the work, has come from testing the main hypothesis, $\mathrm{H}_{1}$, that genderneutral communication affects overall brand equity. In addition, to confirm a positive effect of the factor on the reference variable, the ANOVA definitively proved the statistical significance of the change in the group subjected to the treatment. This outcome seems in contrast with a large strand of literature which considers gender stereotyping as a pivot point for the elicitation of clear gender positioning in companies' communications, and consequently, as a guarantee for greater brand equity (Lieven et al., 2014). Besides, for what concerns the capability of advertising and communication in general to affect $\mathrm{CBBE}$, it seems, all things considered, that this effect is stronger if conveyed through Brand Associations (Krishnan, 1990), that through Brand Attitudes (Cobb-Walgren et al., 1995; Aaker \& Biel, 2013).

What emerged then from the descriptive research, is essentially a substantial and significant gap between Gen Z and Millennials, and Gen Z and Gen X and on the gender issue. Different studies, among which one from Pew Research Center, seem to confirm the fact that Gen Z's perspective on gender non-conformity represents a fundamental divide between this generation and the previous one. The results could be interesting, also if it is considered the importance of Millennials and Generation X as the consumers responsible for the purchase of the majority of goods reserved to children, thus including also children apparel. An outcome as the one proposed by this study could signify that the actual generation of parents is still not ready for a paradigm change, and still anchored to traditional codes of children's clothing.

The findings of the paper should be considered in the light of the following limitations. The first and probably main area of concern regards a typology of errors which is commonly referred as sample errors or selection bias. A possible downfall of the paper could stem precisely from the use of a convenience sample, respect to a probability one, overall considered more suitable for a quantitative type of research. The adoption of the above-mentioned sampling technique was mainly due to time and budgeting constraints. Another fact to be considered, is that the use of 
web-based surveys restricts the set of possible respondents to the ones who actively use the social media through which the survey has been shared. Secondly, being the phenomenon investigated, namely gender-neutrality in the fashion industry, relatively recent, there is still a huge gap of literature on the field. That is why, available previous research on the topic have been quite limited, partly influencing the ability to accurately review the topic in a comprehensive way. For what concerns data gathering, it has been noted that a substantial percentage of respondents did not provide valid answers $(28 \%)$, as they left the questionnaire before the end, leaving several questions unanswered. Even if estimated response time was considered acceptable, different feedbacks highlighted how some repetitive or similar questions of the 7-point Likert scales had generated a drop in respondents' focus.

Future experimentations on the issue, not limited in budget and time, could allow to organize a most statistically significant sample, or maybe set up a more qualitative type of research through face-to-face interviews, in order to deepen and further improve the findings of this study. In the optics of future research, it could be of particular interest to analyze the effects generated in a viewer by a type of communication which does not only eliminate existing gender stereotypes, but even subvert them, providing an overturned image of what is considered as the "acceptable" representation of males and females. As the scheme of the research and the set-up of the statistical analysis appear to be easily replicable, future researchers could take into consideration to change the variable of interests, to investigate other dimensions of the same issue. Less timing constraints, in addition, could increase the possibility to search for scales which could be more suitable to the context of research.

\section{Conclusion}

The study has made evident how classical stereotyped representations of gender could no more be considered as a useful and efficient tool to be used recursively in communication, as decades of academic literature have always affirmed. It is desirable that academic research on the issue will move toward a paradigm shift, focusing more of its effort on an alternative and genderfree type of communication. Brands should take the role of social institutions, in bringing forward the main social battles for which new generations of consumers care more, Gen $\mathrm{Z}$ in particular, following the example provided by some of the major players in the fashion industry. Remaining in the middle, without taking a clear stance on major social concerns is likely to result in a longterm unsuccessful strategy. Particularly important, in this sense, will be the role played by companies in children apparel industry. Breaking the use of this technique is the first step in order to avoid constricting children into the binary paradigm, as well as an opportunity, for brands, to differentiate themselves in a sector where gendered apparel is still prevalent.

\section{References}

Aaker, D. A., Stayman, D. M., \& Vezìna, R. (1988). Identifying feelings elicited by advertising. Psychology and Marketing.

Aaker, D. A., (1991). Managing Brand Equity. New York, NY, The Free Press

Aaker, D. A., (1992). The Value of Brand Equity. Journal of Business Strategy, 13, 4.

Aaker, D. A., \& Biel, A. L. (2013). Brand Equity and Advertising: Advertising's Role in Building Strong Brands. Psychology Press.

Accenture. (2018). Brands Still Matter: Uncovering the Relevance of Brands in US Food and Beverage. Accenture Strategy.

Bain \& Company. (2018). Luxury Goods Worldwide Market Study.

Bravo, R., Fraj, E., \& Martinez, E. (2007). Family as a source of consumer-based brand equity. The Journal of Product and Brand Management, 16(3), 188-199.

Brown, S. P., \& Stayman, D. M., (1992). Antecedents and consequences of attitude toward the ad: A meta-analysis. Journal of Consumer Research, 19(1), 34-50.

Bruner, G. C., \& Hensel, P. J. (2019). Marketing Scales Handbook. American Marketing Association, Chicago.

Chang, H. H. (2008). The antecedents and Consequences of Brand Equity in Service Markets. Asia Pacific Management Review. 
Chaudhuri, A. (1995). Brand equity or double jeopardy?. Journal of Project and Brand Management, 4(1), 26-32.

Cobb-Walgren, C. J., Ruble, C. A., \& Donthu, N. (1995). Brand equity, brand preference, and purchase intent. Journal of Advertising, 24(3), 25-4

Crane, D. (2000). Fashion and Its Social Agendas: Class, Gender, and Identity in Clothing. Chicago University Press, Chicago.

Darley, W. K., \& Smith, R. E., (1995). Gender differences in information processing strategies: an empirical test of the selectivity model in advertising response. Journal of Advertising, 24(1), 41-59.

De Carlo, M. (2018). Scientific Inquiry In Social Work. Open Social Work Education, Roanoke VA, 275-276.

Edell, J., \& Burke, M. C. (1987). The Power of Feelings in Understanding Advertising Effects. Journal of Consumer Research, 14(3), 421-433.

Faircloth, J. B., Cappella, L. M., \& Alford, B. L. (2001). The effect of brand attitude and brand image on brand equity. Journal of Marketing Theory and Practice, 9(3), 61-75.

Feiereisen, S., Broderick, A. J., \& Douglas, S. P. (2009). The effect and moderation of gender identity congruity: Utilizing 'real women' advertising images. Psychology and Marketing, 26(9), 813-843.

Flaherty, K. E., \& Pappas, J. M. (2000). Implicit Personality Theory In Evaluation of Brand Extensions. Psychological Reports, 86, 807-818.

Fugate, D. L., \& Phillips, J. (2010). Product Gender Perceptions and Antecedents of Product Gender Congruence. Journal of Consumer Marketing, 27(3), 251- 261.

Gardner M. P. (1985). Does Attitude Toward the Ad Affect Brand Attitude under a Brand Evaluation set?. Journal of Marketing Research, 22(2), 192-198

Huhmann, B. A., \& Limbu, Y. B. (2016). Influence of gender stereotypes on advertising offensiveness and attitude toward advertising in general. International Journal of Advertising, 35(5), 846-863.

Keller, K. L. (2013). Strategic Brand Management: Building, Measuring and Managing Brand Equity. Upper Saddle River, NJ: Prentice Hall.

Kim, E., Ratneshwar, S., \& Thorson, E. (2017). Why Narrative Ads Work: An Integrated Process Explanation. Journal of Advertising, 46(2), 283-296.

Krishnan, H. S., \& Chakravarti, D. (1990). Humour in Advertising: testing Effects on Brand Name and Message Claim Memory. AMA, Educator's Conference Proceedings.

Lassar, W., Mittal, B., \& Sharma, A. (1995). Measuring Customer-Based Brand Equity. Journal of Consumer Marketing, 12(4), 11-19.

Lieven, T., Grohman, B., Herrmann, A., \& Herrmann, J. R. (2014). The effect of brand gender on brand equity. Psychology and Marketing, 31(5), 371-385.

MacKenzie, S.B., Lutz, R. J., Belch, G. E. (1986). The role of attitude toward the ad as a mediator of advertising effectiveness: A test of competing explanations. Journal of Marketing Research, 23(2), 130143.

Miller, S. J., Mazis, M. B., \& Wright, P. L. (1971). The Influence of Brand Ambiguity on Brand Attitude Development. Journal of Marketing Research, 8(4) 455-459.

Orth, U. R., \& Holancova, D., (2003). Consumer response to sex role portrayals in advertisements: Effects of incongruity and prejudices on emotions and attitudes. Journal of Advertising, 32(4), 77-89.

Rashotte, L. S. (2003). Written versus visual stimuli in the study of impression formation. Social Science Research, 32, 278-293.

Ray, M. L. (1982). Advertising and Communication Management. Englewood Cliffs, NJ: Prentice-Hall, Inc.

Van Horen, F., \& Pieters, R. (2017). Out-of-category Brand Imitation: Product Categorization Determines Copycat Evaluation. Journal of Consumer Research, 44(4), 816-832.

West, C., \& Zimmerman, D. H. (1987). Doing gender. Gender Soc. 1(2), 125-151.

Yoo, B., \& Donthu, N. (2001). Developing and validating a multi-dimensional customer-based brand equity scale. Journal of Business Research, 52, 1-14. 